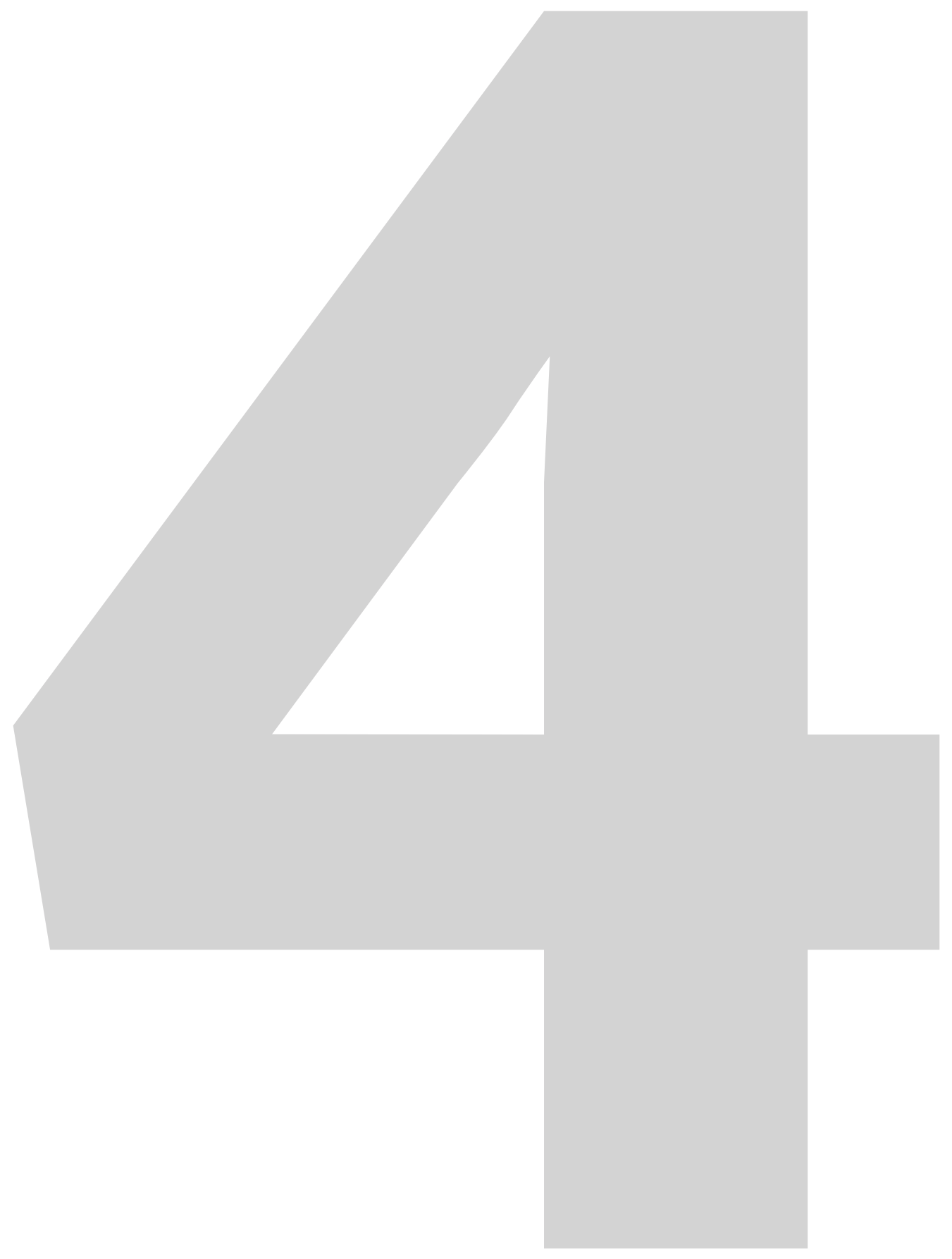




\section{La planta baja, unión de diferencias}

\section{Carlos Mario Pérez Nanclares}

\section{Introducción}

Entre las décadas de los cuarenta y cincuenta se pueden visibilizar en las principales ciudades colombianas cambios que pretendían convertir el aspecto pueblerino de estas en centros urbanos modernos (Botero Herrera, 1996, p. 169). La llegada de la industrialización trae consigo nuevas formas de vida, de trabajar, de habitar. Ciudades como Medellín y Bogotá se ven abocadas a recibir una idea de sociedad inédita hasta el momento que obligó a reflexionar sobre los espacios arquitectónicos y las transformaciones urbanas que se ejecutarían en adelante.

Durante la segunda mitad de siglo, ya la arquitectura moderna en Colombia había sufrido transformaciones y adaptaciones que la llevaron a ser considerada como una "modernidad apropiada" (Vélez Ortíz et al., 2010, p. 10); los edificios aumentaban cada vez más el número de pisos, se diseñaban torres más altas y una tipología edilicia había entrado en auge durante las últimas dos décadas (cincuenta y sesenta): la torre plataforma, que aparece como opción adecuada a las condiciones urbanas de la época.

A comienzos de la década de los setenta aparece el rascacielos en la ciudad, aquel que supera en pisos habitables el promedio de edificaciones del paisaje urbano, que sobresale en la distancia y que se construye como respuesta a una confluencia de factores, que van 
desde lo económico hasta lo tecnológico. Edificios que se comienzan a construir desde condiciones urbanas propias de ciudades con una estructura formal definida por las leyes de Indias, con trazados reticulares, dimensiones de manzana pequeñas, estrecha sección de vías y una excesiva subdivisión predial que repercute, hoy en día, en una compleja forma de las parcelas. Esto determina condiciones difíciles para la construcción e inserción urbana de edificios altos y reclama alternativas de diseño y variaciones tipológicas que clarificaran la relación que se da a través de los pisos bajos entre una entidad masiva como es el rascacielos y otra como es lo urbano.

Al observar los primeros edificios de este tipo, diseñados para Medellín y Bogotá, se hace evidente la aplicación de principios universales que ayudan a la solución de la problemática antes descrita, referenciados en la forma de los rascacielos construidos en ciudades como Nueva York y Chicago; sin embargo, las fuentes consultadas y los análisis realizados por esta investigación no encuentran en ningún caso alusión directa por parte de sus diseñadores a las situaciones que motivaron la diferenciación de las plantas bajas con respecto al conjunto de plantas típicas como un asunto, entre otros, de relación entre la torre y la ciudad.

Este trabajo entonces formula como hipótesis que la relación existente entre el rascacielos y la ciudad requiere un tipo de espacio que oscila su carácter entre lo público y lo privado, siempre presente en las plantas bajas, las cuales adquieren la condición de plantas urbanas, "al incorporar la arquitectura en el espacio público y el espacio público en la arquitectura" (Henao y Mayorga, 2008, p. 72). Un espacio que tiene como función mediar entre los volúmenes que componen el conjunto para que, a pesar de las difíciles condiciones urbanas, los rascacielos se perciban como elementos independientes, con un edificio bajo yuxtapuesto, en lo que se constituye como una variación tipológica de su antecesor, la torre plataforma; de esta manera, se instala como un nuevo tipo de edificio, el rascacielos, adecuado a las condiciones urbanas y arquitectónicas de ciudades como Medellín y Bogotá.

Interesan en esta investigación los primeros edificios construidos en Colombia, considerados rascacielos, el Edificio Coltejer, y el concurso para escoger los diseños de este 
en Medellín en 1968 se establece como el objeto apropiado para realizar los análisis; de igual manera, el concurso para elegir los diseños del edificio Avianca en Bogotá, como un importante antecedente. Ambos son pioneros y exponentes de una tipología que se utilizó durante muy corto tiempo, en una etapa crucial para la modernidad en Colombia, la década de los setenta, en la cual se construye arquitectura considerada de "continuada tradición moderna, denominación que abarca las obras que mantienen la concepción moderna de espacio, pero que acuden a estrategias formales, cuya apariencia volumétrica y consistencia visual presentan una clara diferencia con la llamada modernidad consistente" (Vélez Ortíz et al., 2010, p. 29).

Estudiar el concurso del edificio Avianca, representa una oportunidad de entender la relación entre los rascacielos y la ciudad a través de su plantas bajas, pues para la construcción de un rascacielos con las cualidades formales y la escala requeridas por estos edificios, no bastaba solo con establecer una compatibilidad formal con el entorno, a través del edificio bajo yuxtapuesto o la plataforma, sino que también implicaba resolver asuntos urbanos más complejos, que hicieran frente a situaciones que, en otras cosas, podrían considerarse inéditas: la escasa sección de las vías, la tortuosa forma del lote y su poca área en relación con los generosos predios ocupados por los rascacielos neoyorquinos, contar con la inminente peatonalización de la calle 16 en Bogotá, contigua al lotes, si bien hasta la época fue vehicular, presentaba un uso peatonal predominante. Aunque lo verdaderamente particular acá sería el poner en consideración los resultados urbanos de la práctica de perforar las manzanas para generar pasajes entre ellas y permitir flujos peatonales internos para crear así verdaderos laberintos de comercio entre las calles, lo cual para la época ya era común.

También en Medellín, el concurso del Edificio Coltejer se encuentra directamente relacionado con proyectos denominados premodernos, con los cuales comparte las características de su entorno, por ser vecinos, construidos durante la década de los cuarenta, como La Bastilla, Bemogú y Fabricato, o con la torre plataforma, donde esta última opera como dispositivo de ajuste al lote con un mínimo impacto formal, en algunos casos perforados por una $\mathrm{L}$ que funciona como hall de acceso y pasaje comercial, cuando el edificio es 
construido en esquina como ocurre con los edificios de Seguros Bolívar, BCH, Coltabaco o La Ceiba, entre otros, construidos en Medellín durante la época calificada como modernidad consistente (Vélez Ortíz et al., 2010, p. 29), entre 1947 y 1970. Esta tipología, como conjunto, pierde sentido cuando el edificio alcanza la condición de rascacielos, pues la esbeltez que los caracteriza hace que la plataforma no opere como lo hace con edificios de menores proporciones. Un edificio como el Coltejer tiene entonces un problema de fondo, por cuanto se debe poner el volumen principal del conjunto, la torre, sin mayores mediaciones en el suelo, y cabe preguntarse al respecto algunos asuntos fundamentales: ¿qué dispone?, ¿cómo lo pone?, ¿dónde lo pone? y ¿qué papel juega ahora la plataforma en el conjunto?

Las mismas inquietudes se plantean en torno al proyecto del edificio Avianca. Esta se clasifica dentro de la tipología torre plataforma; sin embargo, la relación entre sus elementos es diferente a la que se da en esta misma tipología, cuando es utilizada en edificaciones de baja altura.

En ella se visualizan dos cuerpos, cuya relación es fuerte y coherente; la plataforma ya no opera como tal, es más bien una extensión de la torre en las plantas bajas, un edificio bajo yuxtapuesto y la torre llega franca hasta el piso, aspecto que establece jerarquía sobre el resto de componentes del conjunto, incluso, sobre las edificaciones que componen el entorno del Parque Santander o como antiguamente se denominaba, Plaza de las Hierbas, el cual cuenta con un valor histórico de gran peso. El edificio Avianca se localiza en uno de sus costados en un predio esquinero, sobre la carrera séptima con la calle 16.

Para finales de la década de los sesenta, el entorno del parque ya contaba con la variedad estilística que lo caracteriza hoy en día, pues a las edificaciones de carácter religioso y origen colonial como la Iglesia de San Francisco (1556) y la Iglesia La Veracruz (1546-1748) se fueron sumando edificios modernos producto de la intervención de las más importantes firmas de arquitectos del momento; el edificio de la Nacional de Seguros (Obregón y Valenzuela, 1959), Museo del Oro (Esguerra, Saénz, Urdaneta y Samper, 1968), Banco Central Hipotecario (Esguerra, Saénz, Urdaneta y Samper, 1967), Jockey Club (Cuéllar Serrano Gómez, 1939), entre otros. 
Ambos edificios, Avianca y Coltejer, abrieron campo entre sus predecesores en medio de fuertes críticas. German Téllez expresa, al referirse en una entrevista para la revista Escala 32, que "[...] un buen síntoma de la modernidad ha sido siempre, en todas partes, el de torcerle el pescuezo a la tradición y aplastarla luego bajo el peso de la nueva arquitectura" (1969, p.), al referirse a los asuntos que enfrentaron proyectos como el edificio Avianca y el Edificio Coltejer, al insertarse en ciudades con las características urbanas de la ciudad colombiana, que obligaron a romper con cánones preestablecidos aferrados a la tradición. Y es que desde la presentación misma de los concursos, las críticas hacia las propuestas presentadas ponían en tela de juicio el impacto urbano que generaba la aparición de piezas arquitectónicas de semejante magnitud. Los críticos suponían, a partir del momento, un maremágnum de rascacielos a construirse en los centros de las dos principales ciudades, en lo que llamaron una versión sabanera del fenómeno ocurrido en New York, durante el auge económico de la década de los veinte, cuando ya la modernidad local había sufrido un proceso de adaptación reedición y acomodación a las posibilidades técnicas, económicas y a las especificidades culturales de nuestro contexto social, pudiendo hablarse de una "modernidad apropiada", específica y particular".

En el caso del concurso para el Edificio Coltejer, las críticas se enfocan en el valor de la pieza arquitectónica que reemplaza. El Teatro Junín, construido en 1924 por el arquitecto belga Agustín Goovaerts, mostraba un rico estilo francés en lo que fue una de las expresiones más destacadas del estilo republicano en la ciudad, y fue demolido para dar paso a una torre de 35 pisos en un sector del centro financiero de la ciudad que ya había consolidado una arquitectura de mediana escala; sin embargo, ya la construcción del edificio Avianca había calmado los ánimos frente al impacto generado por la aparición de rascacielos en ciudades como Medellín y Bogotá. Uno de los asuntos más discutidos en su momento fue la forma adjudicada a la torre. En un artículo publicado en noviembre de 1968, titulado "El peligro del formalismo", el crítico venezolano Juan Pedro Posani destaca la arquitectura generada en Colombia durante las últimas décadas, a la cual considera, la más avanzada de Suramérica, (p.32) y los peligros que para ello conlleva la propuesta elegida como ganadora, en la cual el desbordamiento de formalismo es evidente. Este hecho advierte sobre la confusión de una arquitectura con carácter, con una arquitectura como imagen, en la 
que se hace propaganda del cliente y del arquitecto, en la que se privilegia la intensión de brindar originalidad formal al proyecto.

Los críticos del edificio Avianca se mostraban inconformes con el proyecto escogido, sobre el cual decían que planteaba una pieza fuera de escala que irrespetaba las edificaciones coloniales vecinas y el mismo sitio donde se ubicaría el edificio, un solar que años atrás albergara el que fuera el Hotel Regina, destruido por los disturbios del 9 de abril de 1948. Dicho críticos calificaron la torre como un edificio sensacionalista que solo pretendía imponer su belleza. El artículo titulado "Historia íntima de un edificio", publicado en 1975 en la revista Escala ( $\left.\mathrm{N}^{\circ} 44\right)$, escrito por el mismo Germán Samper, -parte del equipo de diseño del edificio- expone los apartes más relevantes de la polémica.

Por otro lado, causa extrañeza la indiferencia de la crítica del momento con el tema planteado por esta investigación. Las discusiones se centran en asuntos formales y, de manera enfática, en la altura de la pieza arquitectónica más destacada del conjunto, comprensible si se tiene en cuenta el impacto visual que esta genera en el paisaje urbano de ciudades que, como Medellín y Bogotá, cuentan para la época con un skyline relativamente bajo (si se compara con la ciudad moderna norteamericana). Son ausentes las críticas que se centren en la relación entre los rascacielos y la ciudad más allá de lo puro visual o formal; ningún escrito se expresa sobre la manera como dos entidades masivas, perpendiculares entre sí, entran en contacto físico, ¿qué ocurre allí?, ¿cuáles son sus repercusiones y qué exigencias plantea a los arquitectos diseñadores? Más bien, son recurrentes en las publicaciones los esquemas de comparación entre los rascacielos construidos alrededor del mundo y sus diferentes alturas, obviando sus entornos urbanos y sus sistemas de relación en las plantas bajas, y se muestra como trofeo la pieza esbelta de la torre, como si compitieran por el rascacielos más alto.

\section{Metodología}

La metodología, empleada para el desarrollo de esta investigación, comprende actividades que en esencia apoyaron los análisis del objeto de estudio. El orden como se listan 
no representa necesariamente un orden de ejecución de estas; en primer lugar la consulta constante y rigurosa de las fuentes bibliográficas, citadas en los párrafos anteriores, nutrió de un acervo teórico la construcción del texto y la sustentación de los análisis. Lo anterior permitió la construcción del cuerpo teórico y los antecedentes; además, se estableció un marco temporal con el propósito de rastrear la bibliografía, propia de la época, de donde se extrae información histórica sobre las características originales del lugar, las condiciones de las empresas dueñas de los proyectos, las condiciones urbanas, la crítica realizada a través de periódicos, publicaciones en serie y revistas, así como en fotografías tomadas durante la época, cuya fuente principal fue el archivo histórico fotográfico de la Biblioteca Pública Piloto de Medellín.

La búsqueda y análisis de documentos y material proyectual original que reposa en el Archivo Distrital de Bogotá, el repositorio de la Biblioteca Pública Piloto, la planoteca de la Biblioteca Efe Gómez de la Universidad Nacional (sede Medellín) y el archivo de la Secretaría de Planeación de Medellín permitieron indagar sobre la manera de pensar de los arquitectos diseñadores y su posición frente al problema planteado. Allí se pudo establecer, a partir del cuidadoso trabajo consignado en la construcción de las perspectivas, sobre todo de los primeros niveles del conjunto, la importancia que para ellos tenía la manera de resolver las plantas bajas, como un elemento de relación con la ciudad.

La visita a los dos rascacielos construidos en Medellín y Bogotá, que forman parte del conjunto de edificios objeto de estudio de esta investigación, así como otros construidos por los arquitectos participantes en el concurso, años después, permitió reconocer la importancia que, a pesar de las críticas al momento de su construcción, se le hace a los rascacielos con respecto al lugar que ocupan y sus respectivos entornos urbanos, así como la constatación de características tipológicas y calidades espaciales que no se alcanzan a establecer con claridad, si los análisis se basaran solo en una lectura a partir de los planos y las fotografías.

Se hizo una recopilación y reconstrucción de información planimétrica original de los proyectos objeto de análisis; además, se consideró el estudio de aproximadamente 11 edificios diseñados, dos de ellos construidos, en los cuales los equipos de arquitectos 
participantes dispusieron del amplio repertorio adquirido durante más de dos décadas de trabajo. Esto convirtió los concursos en laboratorios proyectuales con un rico acervo de nociones, sobre todo para la resolución de las plantas bajas. Lo anterior se complementó con el estudio de algunos de los planos arquitectónicos y estructurales originales, utilizados para la ejecución de las obras, lo cual da cuenta de las dificultades y decisiones tomadas en obra, algunas en favor del logro del objetivo de brindar condiciones particulares a las plantas bajas a través de variaciones estructurales radicales; la reconstrucción virtual, en modelos tridimensionales y el análisis gráfico de la información extraída de las revistas Escala y dpa fueron la principal fuente de información para esta reconstrucción.

Finalmente y como un ejercicio novedoso para el autor, la construcción del plano en alzado de los edificios, aplicando lo que Alfonso Pérez Méndez —en el ejercicio denominado La sección entre paréntesis (2012) - plantea como método al dibujar secciones "donde se bloquean en negro todas los espacios del edificio que no estén preestablecidos, el espacio denominado "tara", que casi nunca tiene especificaciones previas. Ese espacio que con frecuencia es el único donde el arquitecto tiene libertad, es un espacio donde la ausencia de requerimientos abre la posibilidad de usar la inteligencia arquitectónica" (Pérez-Mendez, 2012.).

También podría compararse el procedimiento anterior con la construcción de un plano "Nolli" en alzado, retomando la idea de Giambattista Nolli, quien dibuja el plano de Roma y representa los espacios públicos cerrados, como la columnata de la plaza de San Pedro o la del Panteón, como espacios públicos abiertos, es decir, no mostrando la idea de llenos y vacíos, sino de espacios públicos y privados, lo cual hasta la modernidad fue pertinente mostrar solo en planta, pues los espacios públicos eran exclusivos del suelo o del primer nivel. Esta situación cambió con la llegada de los rascacielos que se vieron en la necesidad de sumar plantas de uso público próximas al suelo, con el fin de establecer, entre otros asuntos, mediación entre la torre y la ciudad, lo que posibilita la construcción de un plano Nolli en altura, un corte con áreas bloqueadas con negro, donde se muestra cómo el espacio de carácter público asciende para dejar la exclusividad del primer nivel. 
Es de resaltar la gran ayuda de este tipo de dibujos para establecer la incidencia que ejerce sobre todo en los diseños de las plantas bajas del Edificio Coltejer, la práctica de perforar las manzanas para generar pasajes entre ellas y permitir flujos peatonales internos, así como la acomodación a las condiciones topográficas del predio. La revisión de la obra arquitectónica de Germán Samper - autor de los dos proyectos construidosfue fundamental para entender los conceptos que llevaron a concebir las plantas bajas como elemento de relación entre los rascacielos y la ciudad.

\section{Discusión}

En 1962 se realizó la convocatoria pública para el concurso de diseño del anteproyecto para el edificio Avianca, en el cual participaron cinco proponentes, compuestos por firmas de arquitectos reconocidos a nivel local. El objetivo buscaba construir una sede digna y representativa de la primera aerolínea de Latinoamérica; muchas críticas y debates se abrieron en torno a la magnitud de la torre, el primer rascacielos por construirse en Bogotá; sin embargo, poca o nula mención se hace sobre las repercusiones urbanas de las soluciones propuestas para las plantas bajas del edificio. El concurso logró su objetivo de elegir una propuesta para el proyecto, pero en realidad fue más allá, se convirtió e en un laboratorio proyectual que marcaría un precedente de gran importancia para la construcción de edificios en altura en el país, durante la década de los setenta, con una manera de solucionar las plantas bajas en respuesta al entorno urbano, pero sobre todo acorde con las características formales del conjunto. Podría decirse que logró establecer una propuesta tipológica adecuada a las condiciones de nuestra modernidad.

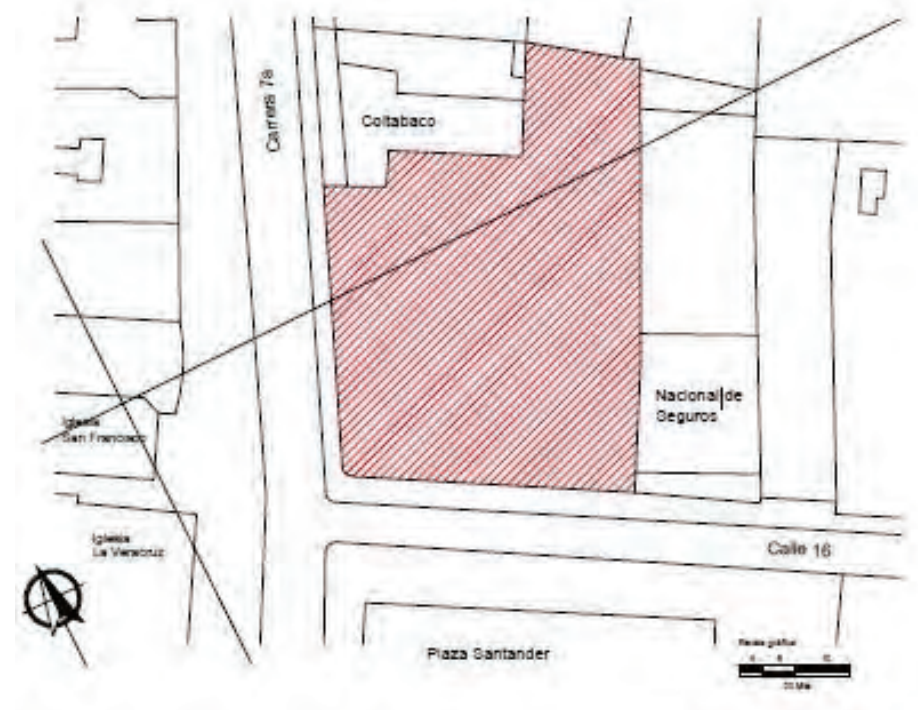

Figura 1. Planta, localización del predio destinado para la construcción del edificio Avianca 
El lote destinado para la construcción del edificio, en una esquina de la carrera Séptima con la Calle 16, en el marco de la Plaza Santander, importante sitio del centro financiero e histórico de Bogotá, contaba con 3360 metros cuadrados y unos vecinos que reclamaban especial atención a la hora de proponer una nueva edificación con las características de un rascacielos a su lado: el edificio de la Nacional de Seguros, con quince pisos de altura, localizado en el costado oriental del lote y diseñado por la firma Obregón y Valenzuela en 1960, emblemático de la tipología torre plataforma cuando está localizada entre testeros, presenta una sola fachada que da hacia la calle 16 y la Plaza Santander; el edificio de Coltabaco, que se encuentra construido sobre la carrera Séptima en el costado norte del lote; las iglesias de La Veracruz y San Francisco, diagonal al costado occidental del predio (que datan de la época de la colonia entre 1556 y 1748; la La Plaza Santander, o como se denominaba antiguamente Plaza de las Hierbas, hito urbano y referente histórico de la capital; finalmente la carrera Séptima, en el costado occidental del lote, que acogió a lo largo de dos kilómetros la mayor cantidad de edificios en altura, construidos en una época importante para la arquitectura moderna en Colombia, por su alta calidad, innovación técnica, espacial y de relaciones urbanas.

Las normas tradicionales europeas que regían en la ciudad, antes de la construcción del edificio Avianca, plantearon como fin último el establecimiento de una homogeneidad volumétrica de las construcciones, a través de restricciones en altura y retrocesos en los primeros niveles, entre otros asuntos; sin embargo, para el concurso de Avianca se formuló una norma específica, la cual planteó un índice de construcción de 8,0 y un índice de ocupación de 0,85, norma que se establece en relación directa con el potencial del lote en términos de rentabilidad. También se definen parámetros de relación con sus vecinos inmediatos, Coltabaco y la Nacional de Seguros, con los cuales debía plantearse un volumen con una altura en una relación de 1 a 3, aunque también podía optar por pegarse a las culatas vecinas. Dicha norma finalmente sería retirada al resultar de su aplicación, en relación con los índices de ocupación y construcción, una torre demasiado esbelta para poder cumplir con las demandas programáticas y las áreas reclamadas por el concurso, según se explica en la serie Érase una vez un edificio (Villate Matiz, 2012, p. 92). 
Las propuestas se resolvieron teniendo en cuenta tres objetivos principales, según se puede entender en el resumen publicado por la revista Proa en su edición número 162 de noviembre de 1963, la cual fue dedicada en exclusiva al concurso. La primera intención fue construir un edificio que fuera representativo para la empresa Avianca; en segundo lugar, representar la capacidad de la arquitectura colombiana, en el momento considerada como una de las más notables de Latinoamérica, en tercer lugar, estaba presentar una propuesta que fuera funcional a la compañía, que respaldara sus servicios fundamentales, como la venta de pasajes, envío de correos, aerogiros, aeroexpresos y que pudiera albergar la cúpula de ejecutivos de la empresa. Uno de los propósitos fundamentales, no explícitos en las bases del concurso, fue la construcción de un edificio que fuera lo suficientemente flexible, productivo y que se promoviera mediante la renta y venta de oficinas, ya que la compañía tenía presupuestado ocupar con su personal solo las plantas bajas y seis niveles de la torre.

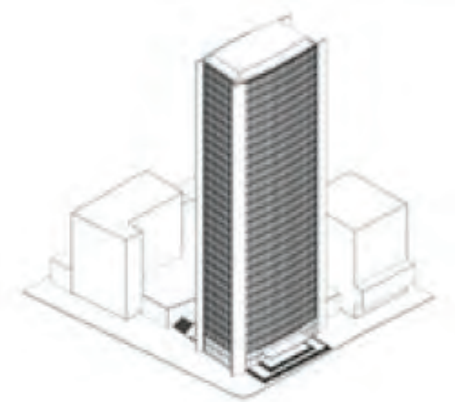

Proyecto presentado por: Germán Samper Gnecco José Prieto Hurtado, Manual Carrizosa, Domenico Parma.

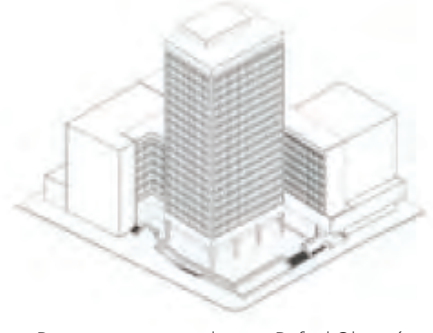

Proyecto presentado por: Rafael Obregón, José María Obregón, Pizano, Pradilla \& Caro.

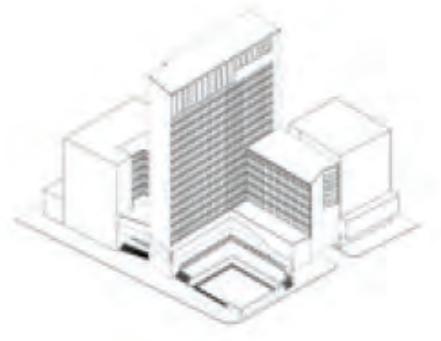

Proyecto presentado por: Gabriel Serrano C Gabriel Largacha M. Guillermo Bermúdez.

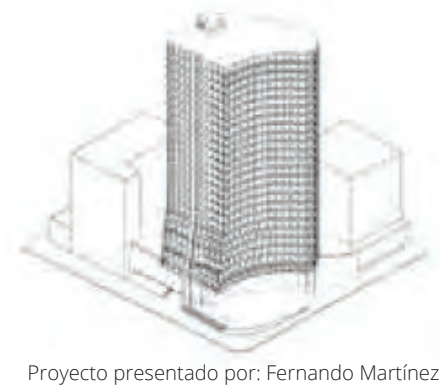
Rogelio Salmona, Guillermo Avendaño.

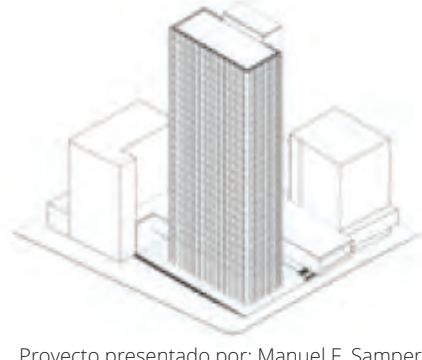

Proyecto presentado por: Manuel F. Samper aime Vélez, Patricio Samper Gnecco, Antonio Castilla.

Figura 2. Isométricos de las propuestas del concurso. 


\section{El vacío urbano como mediador}

Al estudiar referentes de orden internacional, se pueden ver rascacielos que ocupan toda una manzana o gran parte de ella. En Bogotá, en el predio para la construcción del edificio Avianca, en una situación que sería común en casi todos los rascacielos que se construyeron en las ciudades colombianas, se dio una alta subdivisión predial y ya para la década de los sesenta no se disponía de lotes muy grandes; las relaciones con el entorno urbano y las edificaciones vecinas se hacían más complejas.

El vacío urbano que en los proyectos newyorkinos de la década de los cincuenta y los sesenta construidos por firmas como Skidmore, Owings \& Merril, por Mies Van der Rohe, entre otros, acompañara de manera generosa los rascacielos, se tornó aquí en un recurso fundamental de delicado y limitado uso, una alternativa para relacionar la torre con el entorno urbano y las edificaciones vecinas con las características de una ciudad como Bogotá. Las cinco propuestas del concurso presentaban un esquema urbano similar, definido por las circunstancias urbanas del predio, antes expuestas, que hicieron uso del vacío como recurso para mediar entre la arquitectura y la ciudad. Los elementos son dispuestos de manera y orden diferente dentro del lote: tres de ellos localizan la plaza en la esquina de la carrera Séptima con calle 16, una localiza la plaza en el interior del conjunto, como elemento mediador entre el rascacielos y la plataforma sobre la carrera Séptima y otra de las propuestas opta por no configurar un vacío urbano como parte del conjunto, y decide ocupar casi la totalidad del predio.

\section{La plaza en esquina}

En un predio localizado en esquina, situación destacada desde el punto de vista urbano, la disposición de los elementos que componen el conjunto plantean un dilema sobre cuál ocupa el lugar de privilegio, el volumen o el vacío. 


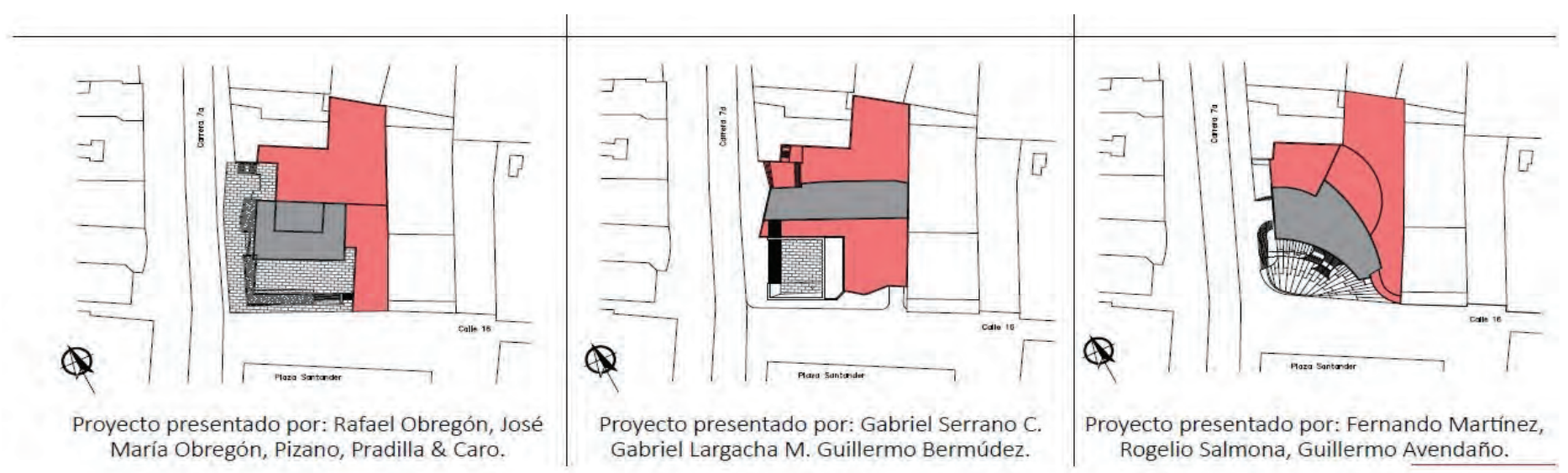

Figura 3. Redibujo de las plantas de primer nivel,

* Se destaca en el redibujo la disposición de la volumetría en el predio, en este caso mostrando la disposición de los elementos, lo que genera el vacío urbano, la plaza, en esquina.

Fuente: elaboración propia basada en imágenes tomadas de la publicación sobre el concurso hecho por la revista Proa No. 162 (noviembre de 1963).

En el caso del concurso para la edificio Avianca, tres propuestas presentaron en su esquema urbano la plaza localizada en la esquina. Los diseños propuestos por el equipo de Rafael Obregón, José María Obregón, Pizano, Pradilla \& Caro, el equipo de Gabriel Serrano C., Gabriel Largacha M., Guillermo Bermúdez y el equipo de Fernando Martínez, Rogelio Salmona, Guillermo Avendaño hacen uso de este recurso, en un intento por destacar, a la par con el edificio propuesto, las iglesias que enmarcan el costado occidental de la Plaza Santander y anticipando la peatonalización de la calle 16.

Las propuestas intentaban responder a las condiciones del entorno, a través de la generación de un espacio vacío que se sume a los atrios de las iglesias vecinas, se responde a la Plaza Santander, con otro espacio abierto, un espacio de transición entre la carrera Séptima y la plaza, al cual se le adjudican los usos de carácter comercial, exigidos por el programa. Desde allí se accede a los servicios de venta de tiquetes aéreos y servicios de correo de la empresa Avianca.Las tres propuestas se catalogan dentro de la tipología torre plataforma; esto ofrece como ventaja que la plataforma, al asumir la forma del predio, deja al edificio alto la posibilidad de ocupar cualquier lugar en el esquema. Esa situación da relevancia a la localización del vacío, ya sea mediando con el exterior o con el interior del 
lote y la plataforma, mediación que gracias a la magnitud de la torre, en este caso, se torna fundamental. Otro asunto de valor en esta configuración es el incremento de la superficie total construida, gracias a que la reglamentación permite aumentar el área determinada por el índice de construcción en una cantidad igual al doble de las superficies liberadas en los primeros niveles y que se destinen al uso público.

Pizano, Pradilla \& Caro, con Obregón y Valenzuela propusieron un esquema de torre plataforma, al cual se le sumaban dos edificios laterales sobre la plataforma, que operarían como volúmenes de acoplamiento a las edificaciones vecinas. En esta propuesta se replegó la torre para conformar una plaza que coincidiera urbanísticamente con el atrio de las iglesias de la Veracruz y San Francisco, colocándola sobre una terraza libre y sobria que resultaba de la bifurcación del plano urbano, que también generaba una plazoleta deprimida, con relación a la calle, gesto característico en las propuestas que la firma venía proponiendo en las plantas bajas de los edificios altos, construido en los bajos del Banco Francés e Italiano y en el Banco Popular, utilizado posteriormente como recurso en la torre Bavaria. Las plazas que genera esta estrategia no desvirtúan el carácter del atrio de las iglesias y al mismo tiempo demarcan el paramento de la calle 16 y la Plaza Santander, al que se ajustan los bloques complementarios que empatan en altura con las edificaciones vecinas.

Cabe resaltar, como antecedente, el caso del Banco Popular, diseñado por Obregón y Valenzuela y construido en 1966, localizado sobre la carrera Séptima, diagonal a lote destinado para el concurso del edificio Avianca, en una parcela de forma irregular, alargada, con tres fachadas hacia la calle, como remate de manzana. El conjunto se encuentra conformado por una plataforma de tres niveles que absorbe la forma del lote, y en la que se localizan usos de comercio y de oficinas, la otra pieza importante es la torre de 13 niveles que en la planta baja cuenta con una calle que atraviesa de manera longitudinal todo el predio; la torre se diferencia, a la vista, de la plataforma gracias a una variación en la fachada de los primeros tres niveles. Aunque torre y plataforma sean dos edificios diferentes, se perciben fusionados, lo cual hace pensar que de haber utilizado el vacío como recurso destacaría la torre en un esquema más próximo a lo que se requeriría dos años más tarde en el concurso del edificio Avianca. 

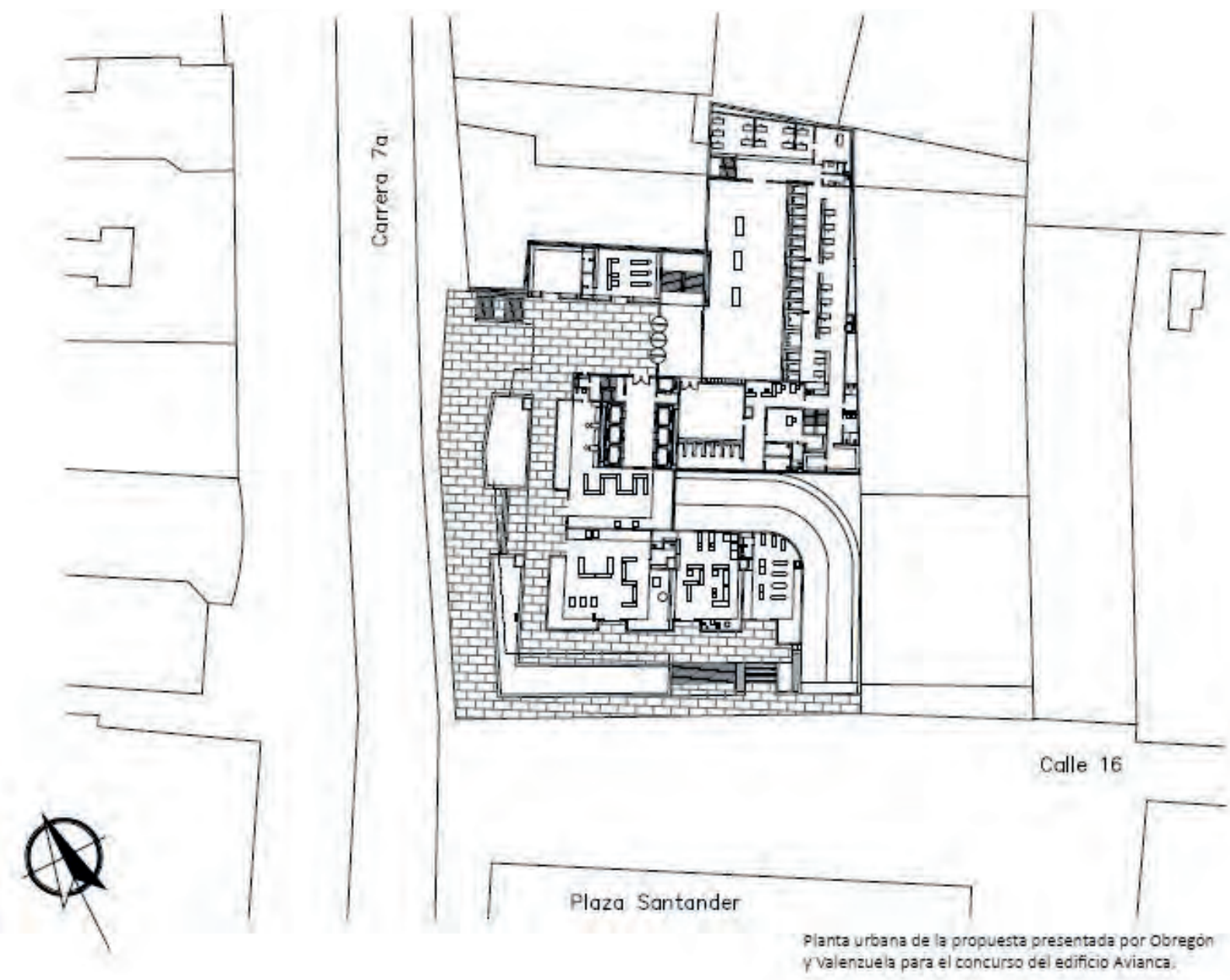

Figura 4. Redibujo de la planta urbana de la propuesta presentada por Pizano, Pradilla y Caro, con Obregón y Valenzuela para el concurso del edificio Avianca

Cuéllar Serrano Gómez y Cía., con Guillermo Bermúdez, proponen un esquema urbano similar al de Obregón y Valenzuela: una torre plataforma con dos volúmenes de acoplamiento a los edificios vecinos. La torre se configura adoptando una forma cóncava que abre y despeja la esquina principal donde se ubica la plaza, en este caso un espacio único por debajo del nivel de la calle, un gran espacio vacío hacia la Plaza Santander, 
coincidente con el atrio de las iglesias vecinas. En ambas propuestas se destaca el hecho de quedar las torres orientadas hacia el parque, determinante urbanístico básico del lugar; se incrementa el área libre en los primeros niveles, en beneficio de la ciudad y del proyecto, ya que a través de la plaza se separa la torre de las iglesias vecinas, se establece una transición entre la carrera Séptima y el espacio abierto de la Plaza Santander y finalmente se evita el empate en un solo paramento de la torre con las edificaciones vecinas; de esta manera, se deja esta función a los volúmenes adicionales propuestos entre otros asuntos para tal fin.

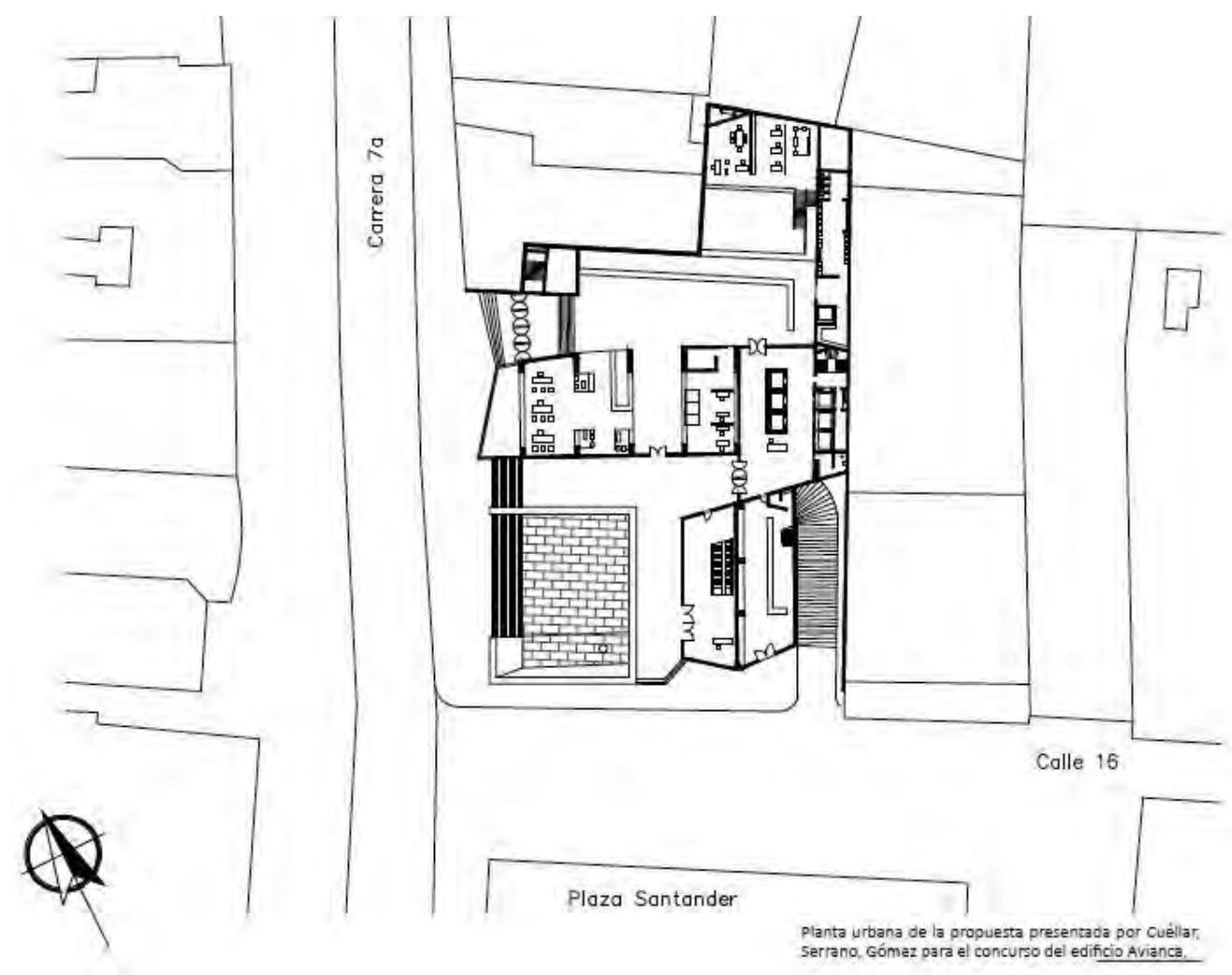

Figura 5. Redibujo de la planta urbana de la propuesta presentada por Cuéllar, Serrano, Gómez y Guillermo Bermúdez para el concurso del edificio Avianca 
Fernando Martínez, Rogelio Salmona y Guillermo Avendaño proponen una torre de volumen notable, aunque de limitada altura en relación con la propuesta ganadora. Sus fachadas de formas curvas terminan coincidiendo con los paramentos de la carrera Séptima y la calle 16. La torre se ubica sobre una plataforma de tres niveles que contienen espacios de servicio público y zonas de reunión. La plaza en la esquina, aunque más discreta y a nivel de la calle, acentúa la participación en el escenario urbano de las iglesias que cierran el parque en su costado occidental; además, prevé la peatonalización de la calle 16, la orientación de la torre que despliega su vista principal hacia los cerros orientales y la plaza próxima a la calle 16 da continuidad al paisaje urbano cercano. La plaza también sirve de vestíbulo.

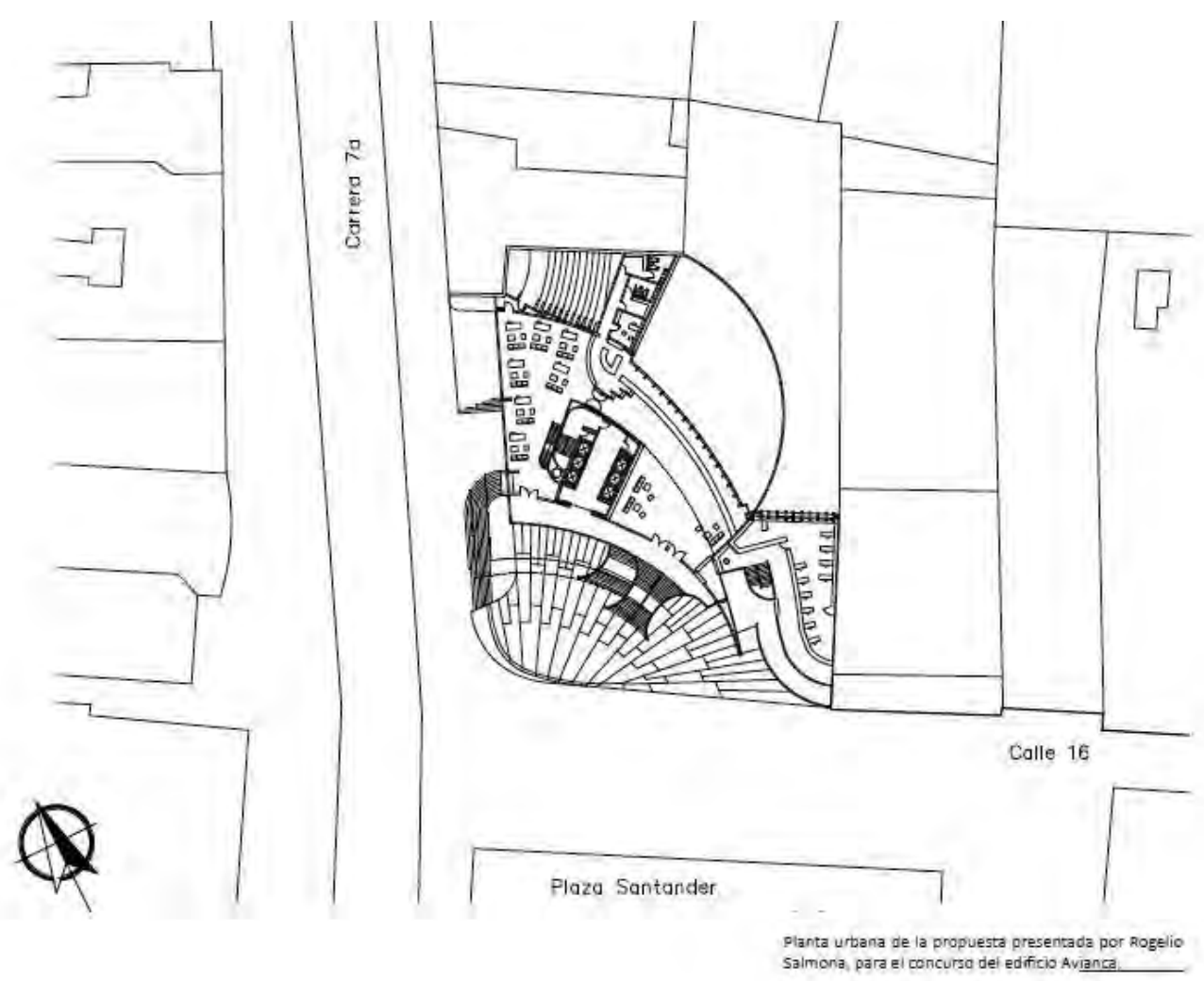

Figura 6. Redibujo de la planta urbana de la propuesta presentada por Fernando

Martínez, Rogelio Salmona y Guillermo Avendaño para el concurso del edificio Avianca 


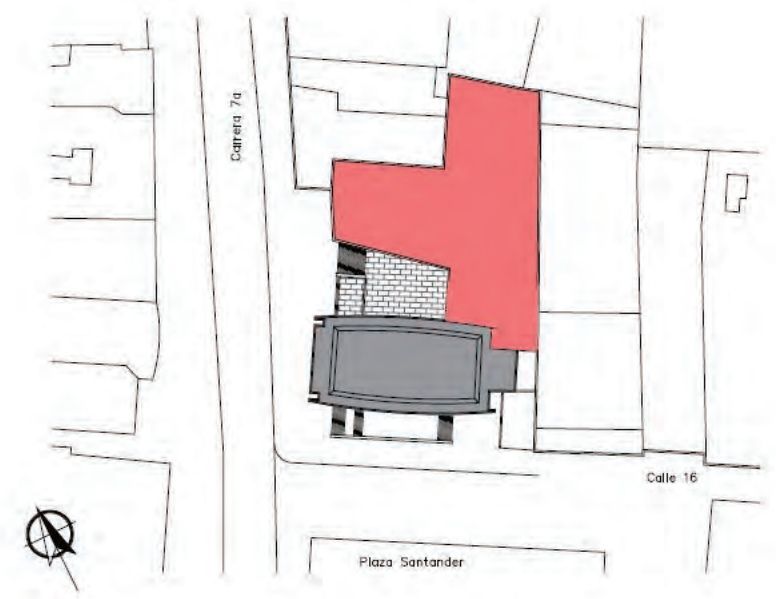

Figura 7. Redibujo de las plantas bajas, con disposición de los volúmenes. Esguerra, Saénz, Urdaneta y Samper.

\section{La plaza lateral}

La propuesta ganadora, presentada por el equipo de Esguerra, Saénz, Urdaneta y Samper, fue la que propuso el edificio más alto, el único considerado como rascacielos dentro del concurso, con una altura de 115 metros. Este edificio, luego de ser construido, se convirtió en el más alto de Colombia para la fecha, lugar que ocuparía hasta la construcción del edificio Coltejer, cinco años más tarde. Los arquitectos se valen de dos recursos para lograr la altura de 34 pisos: el primero marca una gran diferencia con las tres propuestas que plantean la plaza en esquina y es la ausencia de los bloques adicionales propuestos para empalmar en altura con los edificio vecinos, optando por una plataforma de un solo piso de altura que deja el rascacielos como un prisma esbelto $y$ libre, que despeja los espacios bajos muy congestionados en las otras propuestas, y que al ubicar la torre en la esquina en vez de la plaza permite liberar totalmente las cuatro fachadas. Esto da como resultado una volumetría sencilla y un conjunto bastante equilibrado que a pesar de la radical diferencia de altura entre sus componentes se percibe fusionado.

La plaza lateral aparece mediando entre el rascacielos y la plataforma, a manera de vestíbulo-plaza de entrada al conjunto desde la carrera Séptima, dos metros por encima del nivel de la calle, lo que le adjudica también la categoría de mirador. Desde la carrera Séptima se accede a través de unas escaleras que se bifurcan, lo que permite el descenso a los sótanos, a uno de los cuales se accede a través de un vestíbulo interior que al estar por debajo del nivel de la calle y contar con una doble altura que lo relaciona con el hall principal del rascacielos en la primera planta se relaciona visualmente con el entorno urbano gracias a la fachada vidriada en primer nivel. Esto lo constituye en uno 
de los gestos urbanos más significativos de la propuesta y más icónicos del proyecto.

La relación entre todos los elementos que dan carácter urbano a las plantas bajas se da a través del hall principal del rascacielos, el cual en sentido sur-norte conecta la Plaza Santander con la plaza interior del conjunto, y en su costado occidente, en el interior del edificio, se relaciona directamente con el vacío que da hacia el vestíbulo interior del primer sótano. La decisión de permitir el libre tránsito por ese hall convierte tres espacios de distintas categorías en un sistema integrado por la Plaza Santander, la plaza interior, el vestíbulo interior, el hall y las escaleras, sistema que recoge las dinámicas del entorno y que acopla así el conjunto al lugar urbano que ocupa. Esto alude a una de las ideas planteada por Manuel de Solà-Morales i Rubió, quizás trivial como concepción del espacio público, pero de recurrente uso durante la modernidad, que propone para el espacio público el carácter de sistema (2000, p. 22), es decir, de cadena secuencial de espacios libres formando un conjunto unitario.

La propuesta de Manuel F. Samper, Jaime Vélez, Patricio Samper y Antonio Casillas se aproxima a la relación volumétrica del proyecto ganador, aunque no introduce la plaza como parte del conjunto, pues opta por dos galerías laterales a través de las cuales se accede al hall principal del edificio. Su propuesta no considera liberar de manera significativa la planta urbana; sin embargo, en conjunto, es la propuesta más próxima a la ganadora en términos de proporciones y la que establece mejor relación con el edificio Seagram de Mies van der Rohe como antecedente, al plantear una torre limpia que se queda corta en su pretensión de retirarse del paramento.

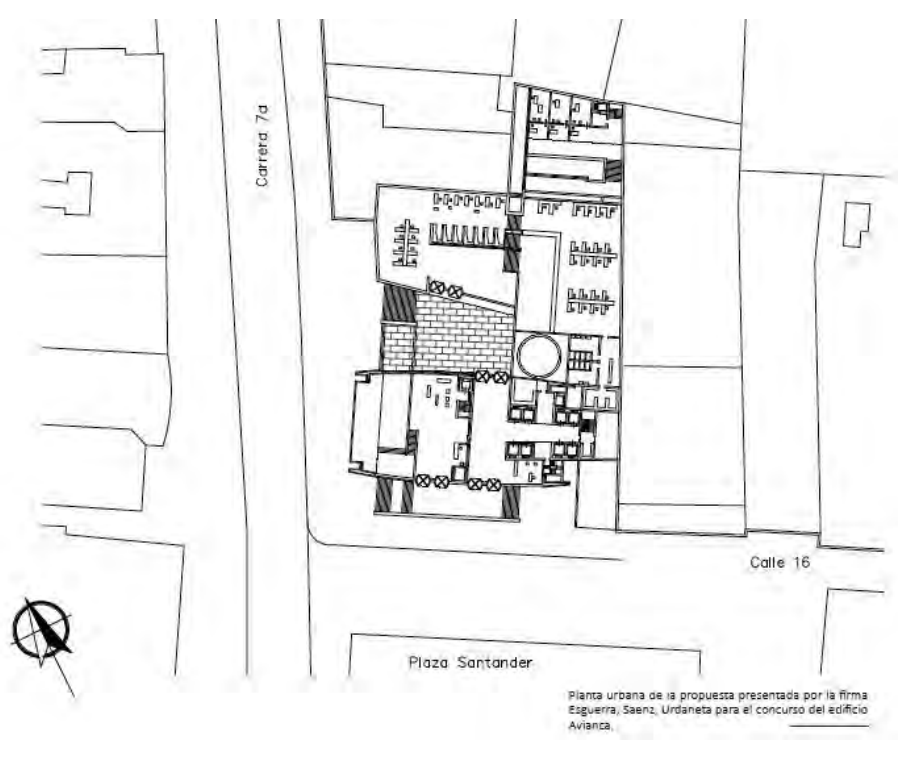

Figura 8. Planta urbana de la propuesta presentada por la firma Esguerra, Sáenz, Urdaneta y Samper, para el concurso del edificio Avianca 


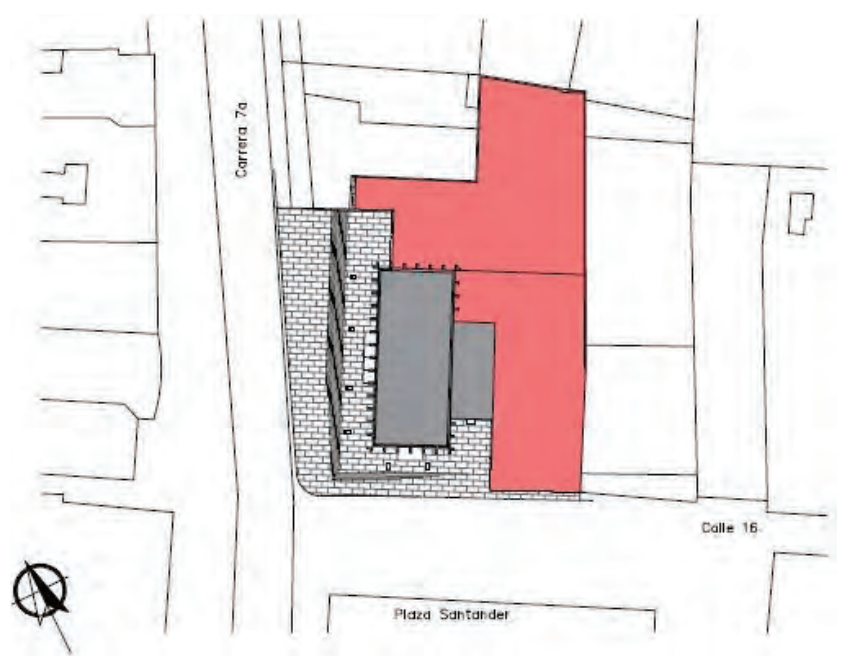

Figura 9. Redibujo de las plantas bajas, con disposición de los volúmenes. Manuel F. Samper, Jaime Vélez, Patricio Samper y Antonio Casillas
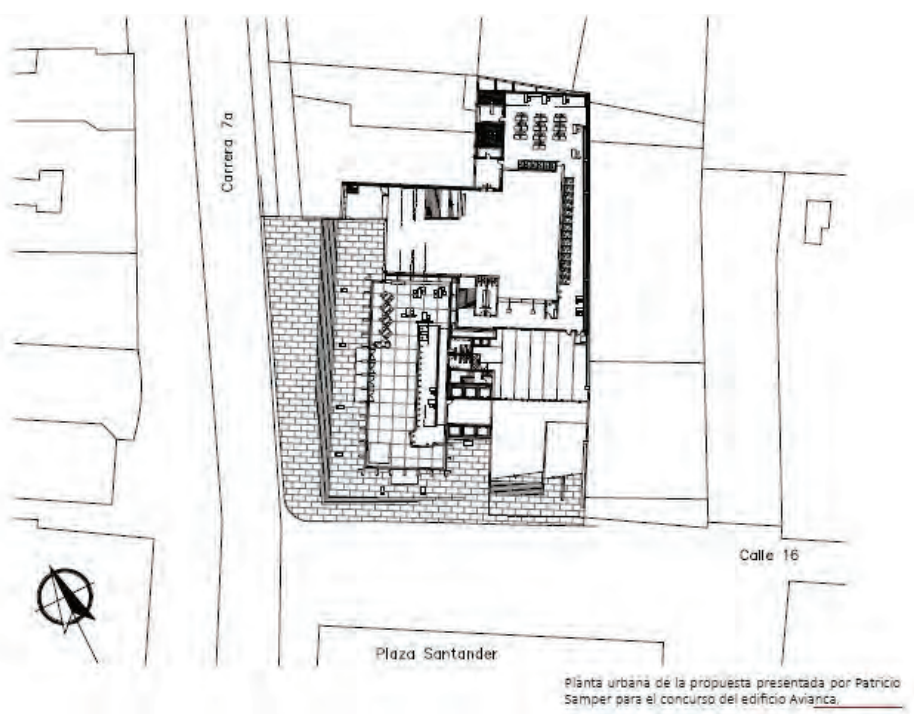

Figura 10. Redibujo de la planta urbana de la propuesta presentada por Patricio Samper para el concurso del edificio Avianca

\section{El carácter público en las plantas bajas}

"La buena ciudad es aquella en que los edificios particulares -sobre todo los buenos edificios particulares-, lo pretendan o no, son elementos públicos, y transportan significados y valores sociales más allá de sí mismos, y en eso está su modo de ser urbanos" (de Solà-Morales i Rubió, 2000, p. 25).

Los edificios más altos que se comenzaron a construir a finales de la década de los sesenta y durante los años setenta en Colombia, al encontrarse en una ciudad con un urbanismo de escasas proporciones y una subdivisión predial excesiva, se ven en la obligación de liberar todo el espacio posible en las plantas bajas. En el caso del edificio Avianca, dadas las apretadas dimensiones del predio y la necesidad de cumplir con un programa que reclama una serie de funciones comerciales y de servicios en los primeros niveles relacionadas con la naturaleza de la empresa, se hace necesario sumar plantas en altura o hacia los sótanos que involucren un carácter público en sus espacios. 
Elementos como el vestíbulo, el hall, las terrazas y escaleras aparecen para componer los pisos que por encima o debajo del nivel de la calle permitirían al transeúnte hacer uso de ellos, fuera o no cliente de los servicios que Avianca pretendía ofrecer en esos espacios.

Las propuestas que para la edificio Avianca se hacen a través del concurso son tímidas en este sentido; el tema de la rentabilidad del suelo en una época de desaceleración económica y el hecho de no tener precedentes una construcción de semejante altura parece haber limitado la audacia de los proponentes frente a una alternativa que les hubiera reivindicado ante la crítica de "manhatanizar" la ciudad, aludiendo a la indolencia urbana de los cientos de rascacielos construidos durante la modernidad en New York, como producto de la ley de zonificación de 1916.

\section{Bifurcación del plano urbano}

Tres de las propuestas presentadas hacen uso de este recurso, aprovechando la pendiente de la calle 16 que entre la carrera Séptima y el edificio de la Nacional de Seguros presenta una diferencia de altura de 1,5 metros aproximadamente. En el caso de la propuesta presentada por el equipo de arquitectos liderado por Rogelio Salmona y Fernando Martínez, la plaza que se genera a nivel de la calle sirve de llegada tanto para el correo, como para el banco, que

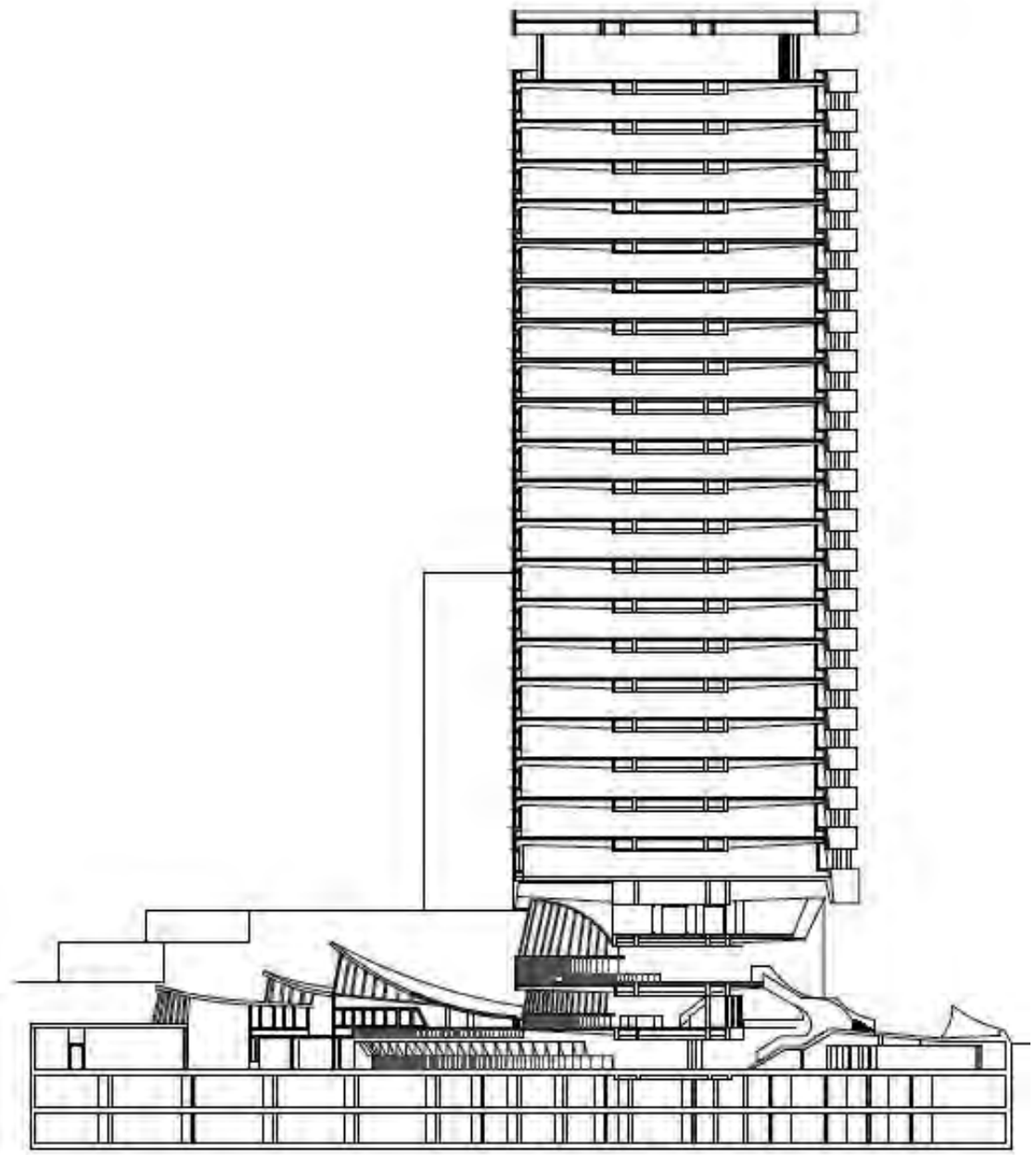

Figura 11. Corte de la propuesta presentada por Fernando Martínez,

Rogelio Salmona y Guillermo Avendaño

* La propuesta fue publicada en la revista Proa No. 162 de noviembre de 1963, en la cual se muestran las escaleras que llevan a la plazoleta y la terraza, resultantes de la estrategia de bifurcar el plano urbano 


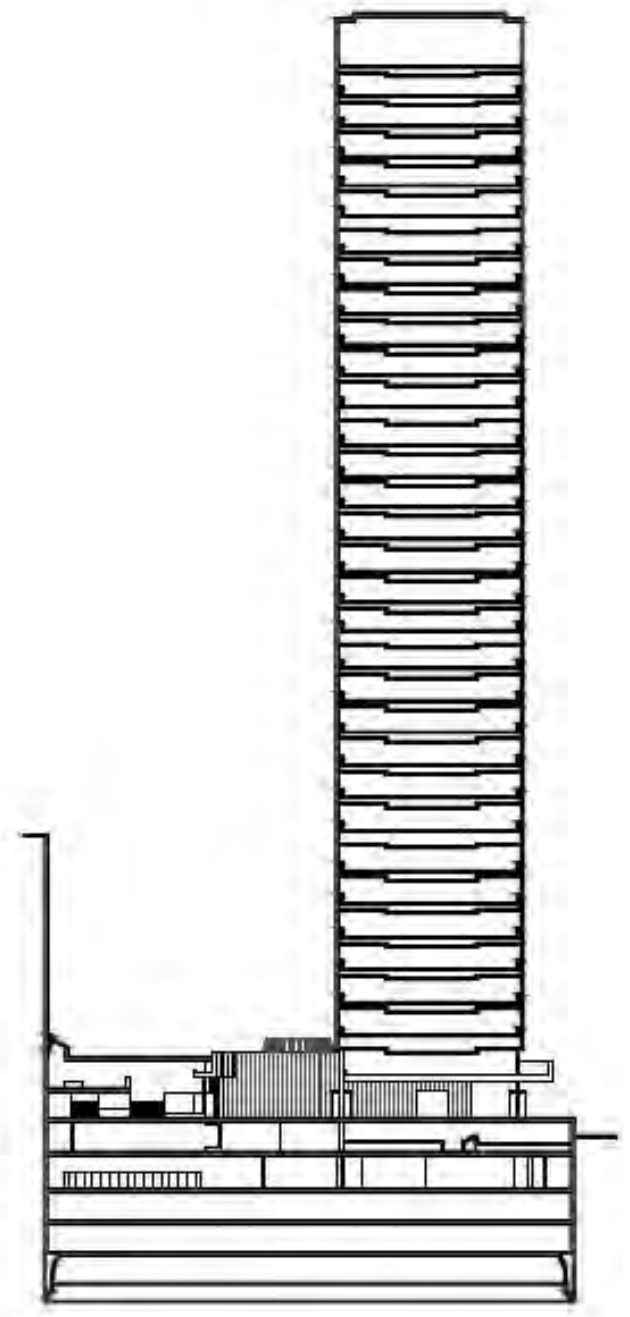

Figura 12. Corte de la propuesta presentada por Esguerra, Saenz, Urdaneta y Samper *Corte publicado en la revista Proa No. 162 de noviembre de 1963, donde se muestra el resultado de reducir la altura de la plataforma, lo que impide la proliferación de espacios de carácter público en altura y propicia la aparición del vestíbulo público en el primer sótano. se ubican en un nivel por debajo de la calle, y como acceso a la venta de pasajes, que establece un nivel por encima de la calle. A estos espacios se accede por una importante escalera pública que forma parte del conjunto arquitectónico.

Obregón y Valenzuela, y Pizano, Pradilla \& Caro proponen unas escaleras públicas que se bifurcan y conectan directamente los espacios elevados y deprimidos con la carrera séptima y con la calle 16; la plaza que se encuentra por debajo del nivel de la calle da acceso a locales de comercio, al hall público de la oficina de correos y al hall de ascensores del edificio. La terraza a la cual lleva el tramo ascendente de las escaleras sirve de antesala a la zona más privilegiada del predio, donde se ubica la venta de tiquetes aéreos de Avianca y las oficinas del banco.

Es esta la única propuesta que hace uso de jardineras, dispuestas a la par con las escaleras, mediando entre los andenes de la calle 16 y la carrera séptima y plazoleta deprimida; esto prolonga el gesto ya construido en el vestíbulo público propuesto para la Nacional de Seguros, extendiendo la relación formal ya establecida por el volumen lateral que se ajusta a la forma del edificio vecino y que implica el único paramento con el borde del lote hacia el costado sur y hacia la Plaza Santander.

La estrategia de un plano elevado y otro deprimido con relación a la calle también es ejecutada por la propuesta ganadora del concurso. El equipo liderado por Germán Samper desarrolló una propuesta de suma elegancia, aprovechando su decisión de colocar la plaza mediando entre el rascacielos, la plataforma y la calle; en primer lugar se eleva la plaza al nivel más alto del predio, en relación con la calle 16, 1,80 metros de altura, instalando una escalera pública sobre la carrera Séptima para acceder a ella. La escalera se bifurca bajando hacia los sótanos, donde se localiza, bajo la torre, el vestíbulo público, que antecede la sala de venta de tiquetes aéreos - mencionado anteriormente- y que se relaciona con el hall de acceso al edificio mediante un vacío en el primer 
nivel y con la carrera Séptima a través de una fachada transparente. Esto crea una relación sistémica entre todos los elementos que componen las plantas bajas, las cuales adquieren un carácter urbano, lo que corrobora que las relaciones de los edificios con el espacio público se resuelven en el ámbito de relación más directa, su planta baja, al incorporar la arquitectura en el espacio público y el espacio público en la arquitectura.

\section{Conclusiones}

A partir de la experiencia relacionada con el concurso del edificio Avianca, queda claro que la relación entre el edificio y la ciudad no se podría resolver entonces con un discreto tratamiento de discontinuidad en el aspecto de la fachada en los primeros pisos, con respecto al resto del edificio, como se hiciera en proyectos denominados premodernos. Esa relación, como lo visionaban los arquitectos antes de la modernidad, cambia y se establece una manera diferente de reflexión al respecto. Aunque algunos elementos de relación formal persisten, el aspecto ornamentado de edificaciones de baja altura cambia por la proliferación de esbeltas torres de diversos usos, con fachadas menos ornamentadas que establecieron mejor correspondencia, con los materiales livianos y de construcción serializada, introducidos por la revolución industrial.

La tipología edilicia había entrado en auge durante las últimas dos décadas (años cincuenta y sesenta), la "torre plataforma", que aparece como opción adecuada a las condiciones urbanas y normativas de la época, comprendida entre las décadas de los cincuenta y los sesenta, aunque influencia la reflexión establecida en torno a la relación de los edificios altos con la ciudad en sus plantas bajas, no opera para los rascacielos sin antes sufrir ajustes. Lo anterior queda demostrado al analizar el concurso para la Edificio Avianca, donde las cuatro propuestas que no salen favorecidas no logran desprenderse de la tipología torre plataforma, y su típica relación formal, en la cual la torre se encuentra sobrepuesta a la plataforma y es esta la que media entre la torre y la ciudad. En vista de lo anterior y dados los requerimientos programáticos y los altos índices de construcción requeridos por el concurso para poder cumplir con el programa, aparecen en consecuencia 
en algunas propuestas, una serie de volúmenes entre la torre y los medianeros, que congestionan el conjunto y no logran clarificar su relación con la ciudad en las plantas bajas.

La propuesta ganadora logra en cambio desprenderse de la recurrente relación formal de la torre plataforma, derivada de la normativa volumétrica restrictiva y entiende el propósito de la nueva norma basada en índices. Esto consigue adecuar dicha interpretación a una propuesta sin precedentes en la ciudad y el país, un rascacielos yuxtapuesto a la plataforma, que involucra elementos de relación como el vacío urbano y la calle interior que, aunados a elementos arquitectónicos de uso interior como los halls, escaleras, jardines, vestíbulos y terrazas, logran componer un sistema que beneficia la relación entre la arquitectura y la ciudad, y que abre la puerta a una serie de edificios altos, en las principales ciudades que recurren a la misma estrategia para adaptarse al lugar urbano que ocupan.

Son los mismos grupos de arquitectos, participantes en el concurso del edificio Avianca, quienes durante la década de los setenta construyeron los rascacielos más notables de la época, llamada modernidad consistente en Colombia. Con esto se pueden identificar en ese grupo de edificaciones las características que se introducen a través de los concursos y se constituyen en verdaderos laboratorios proyectuales, que marcan el camino por seguir, en torno a la construcción de edificios altos de carácter corporativo.

Algunos de los rascacielos que se construyen involucrando elementos de relación en las plantas bajas incorporados por el concurso del edificio Avianca son: la Torre Colpatria, de Obregón y Valenzuela (1979); el Centro de Comercio Internacional, de Cuéllar Serrano Gómez y Cía. (1974); el edificio de Seguros Tequendama, de Pizano Pradilla \& Caro (1970),

Por otro lado, las críticas sobre los edificios considerados rascacielos, así como los análisis, se centran en la comparación de la altura de las torres y la forma adjudicada a esta. Poco se ha discutido y estudiado sobre el papel de las plantas bajas y los elementos de relación urbana que introducen los rascacielos de la década de los setenta. 
El valor de las propuestas y de los laboratorios proyectuales que representaban los concursos estaba en la reflexión urbana y los aportes de las plantas bajas a la relación de esas exuberantes formas con el lugar.

Es de resaltar la poca memoria sobre las enseñanzas y ricas experiencias dejadas por los concursos y posterior aplicación de sus estrategias de relación urbana. Después de que la construcción de ese puñado de rascacielos tuviera algo más de una década de pausa, las nuevas propuestas no involucraron los elementos que le dieron a los rascacielos de la década de los setenta cualidades urbanas excepcionales, siendo indiferentes con el lugar urbano y recurriendo nuevamente a la práctica de principios de siglo, de límites marcados entre lo público y lo privado, frontera que en Avianca, Coltejer, Colpatria y Tequendama se había diluido, tomando lo privado el carácter de lo público, convirtiendo las plantas bajas de los edificios en espacios de uso colectivo. En la actualidad se cierran nuevamente las fronteras al transeúnte y lo público y lo privado toman diferencia, ya no ocupan el mismo lugar.

\section{Referencias}

Botero Herrera, F. (1996). Medellín 1890-1950. Historia urbana y juego de intereses. Medellin: Universidad de Antioquia.

Henao, E. y Mayorga, M. (2008). ¿Planta baja o planta urbana? DPA, (24), 72-76.

Pérez-Méndez A. (2012) La sección entre paréntesis. Notas de clase de maestría en arquitectura, Universidad Nacional de Colombia, Medellín

Solà-Morales M. (2000) Espacios públicos, espacios colectivos. Portafolio 1(1), 20-26. Disponible en: http://produccioncientificaluz.org/index.php/portafolio/article/view/12748/12736

Vélez Ortíz, C., López Chalarca, D., Gaviria Restrepo, M. y Montoya Arango, N. (2010). Arquitectura moderna en Medellín 1947-1970. Medellín: Universidad Nacional de Colombia.

Villate Matiz, C. (2012). Erase una vez un edificio. Bogotá: Uniandes. 